\title{
Single Step Solid-Solid Reaction Scheme for the Synthesis of Cobalt Sulphide-Oxide Nanoparticles in Polymer Matrix
}

\author{
Narendra Rumale ${ }^{1,2}$, Sudhir Arbuj ${ }^{2}$, Govind Umarji ${ }^{2}$, \\ Manish Shinde $^{2}$, Uttamrao Mulik ${ }^{2}$, Anuj Pokle ${ }^{3}$, Dinesh Amalnerkar ${ }^{2 *}$ \\ ${ }^{1}$ ELANTAS Beck India Ltd., Pimpri, India \\ ${ }^{2}$ Centre for Materials for Electronics Technology (C-MET), Panchawati, India \\ ${ }^{3}$ Icon Analytical Equipment Pvt. Ltd., Mumbai, India \\ Email: *amalnerkar@cmet.gov.in
}

Received December 14, 2012; revised January 15, 2013; accepted January 25, 2013

\begin{abstract}
At present, there is considerable interest in polymer-metal chalcogenides/oxides based nano-composites on account of their tunable optical, magnetic, electronic and catalytic properties. Here in, we report a simple single step approach for the in-situ synthesis of combined cobalt sulphide/cobalt oxide in polyphenylenesulphide (PPS) polymer matrix. We have illustrated the suitability of this methodology by reacting commonly available cobalt precursors with engineering thermoplastic, PPS. The cobalt precursor was homogeneously mixed with PPS in the molar ratios of 1:1, 1:5, 1:10, 1:15, respectively, followed by heating the mixtures obtained at the melting temperature of the polymer $\left(285^{\circ} \mathrm{C}\right)$ for six hours. The resultant products were characterized by X-ray Diffractometry (XRD), Field-Emission Scanning Electron Microscopy (FESEM), High Resolution Transmission Electron Microscope (HRTEM), Diffuse Reflectance Spectroscopy (DRS) technique and Fourier Transformation Infra red Spectroscopy (FTIR). Formation of mixed phases viz., sulphide and oxide of cobalt within modified PPS matrix was confirmed by XRD. The resultant nanoparticles of cobalt sulphide and cobalt oxide embedded in the PPS matrix showed crooked and chunk morphology. The optical properties of the resultant nanocomposites indicate the shift in the absorption hump due to nanoscale size effect.
\end{abstract}

Keywords: Polymers; Nanocomposites; Cobalt Sulphide/Oxide; Solid-Solid Reaction

\section{Introduction}

In the recent times metal sulphides-oxides embedded in polymeric matrices have represented a new class of nanostructured materials. These materials combine the properties of the polymer as well as the metal and its corresponding sulphide-oxide and show entirely a different set of properties in comparison to the original materials. These materials coalesce various properties such as optical transparency, magnetism, luminescence, UV-visible absorption etc. leading to exclusive functional materials that can be easily explored for numerous applications in different technological fields [1]. The transition metal sulfide nanomaterials have been the focus of considerable interest due to their unique optical and electrical properties and their wide variety of potential applications in nanoscale devices such as electroluminescence and nonlinear optical devices [2]. Cobalt sulphide-oxides are one of the most complicated systems known due to their number of phases and chemical compositions. Few phases of cobalt sulphide and oxides reported are CoS,

"Corresponding author.
$\mathrm{Co}_{3} \mathrm{~S}_{4}, \mathrm{CoS}_{2}, \mathrm{Co}_{9} \mathrm{~S}_{8}, \mathrm{CoO}, \mathrm{Co}_{3} \mathrm{O}_{4}$ etc. Cobalt sulphide/ oxides are one of the important classes of material which have found direct applications in solar selective coatings, photo detectors, solar cells, biological labeling, Li-ion battery, and magnetic devices etc. $[3,4]$. These materials have gained immense importance in recent time due to their magnetic properties and their use for fabrication of dilute magnetic semiconductor materials. Till date numerous techniques have been used for the synthesis of nanoscale cobalt sulphide and oxide nano-particles separately such as anodized alumina films for growth of cobalt disulphide nanowires by application of two electrical fields [5], colloidal synthesis of hallow nano-cobaltsulphide spheres [6], hallow metal oxides and sulphides by laser ablation in liquid [7], hydrothermal technique [8], biomolecule-assisted hydrothermal process [9], cobalt sulfide in montmorillonite by solid-solid reaction [10], co-precipitation method for generation of cobalt oxide nanoparticles [11,12], chemical bath deposition of thin films [13], $\mathrm{Co}_{3} \mathrm{O}_{4}$ nanowalls by direct heating of cobalt foil on hot plate etc. [14]. In addition to the above, number of methods have been reported for in-situ generation 
of well defined nanoparticles in polymeric matrices such as ring opening metathesis polymerization (ROMP) to synthesize cobalt diblock copolymer [15], atom transfer radical polymerization (ARTP), nitroxide mediated polymerization (NMP), reverse addition fragmentation chain polymerization (RAFT) etc. [16].

In this communication, we report one step approach for the synthesis of cobalt sulphide-oxide nanoparticles in thermally stable polymer matrix of polyphenylenesulphide (PPS) by simple polymer inorganic solid-solid reaction scheme. The polymer PPS has been intentionally chosen as it serves dual purpose-first it acts as a chalcogen source and second it acts as a stabilizing media. The advantage of synthesizing semiconductor nanoparticles in the polymer matrix is that it provides good stabilization action and controls the agglomeration of nano-particles formed within the polymer matrix.

\section{Experimental Details}

The reactant cobalt nitrate was obtained from Merck and was used as received, the polymer polyphenylenesulphide (PPS) with number average molecular weight 10,000 having glass transition temperature $(\mathrm{Tg}) 88^{\circ} \mathrm{C}$ with melting temperature of $285^{\circ} \mathrm{C}$ was obtained from Sigma Aldrich. The material was synthesized by reacting the precursors in the molar ratio of $1: 1,1: 5,1: 10,1: 15$, respectively, for cobalt nitrate and PPS. The materials for each molar ratio were mixed using agate mortar and pastel and a few drops of acetone were added for proper wetting of the reactants. The admixtures thus formed were then heated at the melting temperature of the polymer i.e. $285^{\circ} \mathrm{C}$ for six hours in a muffle furnace under normal atmospheric conditions. The phase identification of the resultant powder products was conducted using X-ray diffractometer (Brucker D5005), using $\mathrm{CuK} \alpha$ radiation. Material in powdered form was used for such analysis. The particle size and the surface morphology of the samples were investigated by HRTEM with FEI Tecnai G2, at an acceleration voltage of $200 \mathrm{KV}$. The samples for HRTEM were prepared by dispersing fine powder of the resultant product in isopropyl alcohol. The dispersion was than coated on carbon coated grid for further analysis. The surface morphology was determined using FESEM, Hitachi, S-4800, the solid samples were used as such for determination. In order to prevent the charging effect associated with FESEM, the samples were placed on carbon tape and coated with thin Au film. The Infrared study was carried out using Fourier transformation Infrared spectrophotometer (FTIR-Perkin Elmer Spectrum 100). Approximately $500 \mathrm{mg}$ of sample was mixed with dried $\mathrm{KBr}$ powder, the mixture was grinded and pellets were formed for further IR analysis. The UV-DRS spectra were recorded on UV 3600, Shimadzu UV-VISNIR spectrophotometer for solid powder samples.

\section{Results and Discussion}

Figure 1 depicts the XRD pattern obtained for the resultant products. Prominent formation of $\mathrm{Co}_{3} \mathrm{O}_{4}$ for the $1: 1$ and 1:5 ratio of ratio of cobalt nitrate to PPS is observed (Figures 1(a) and (b)). The diffraction peak at $2 \theta$ value of $36.8,44.8,59.3$ and 65.2 respectively corresponds to (311), (400) planes, (511) and (440) indicating the formation of cubic $\mathrm{Co}_{3} \mathrm{O}_{4}$ (JCPDS No.42-1467). For samples corresponding to $1: 10$ and $1: 15$ precursor to PPS ratio, mixed phases of $\mathrm{Co}_{3} \mathrm{~S}_{4}$ and $\mathrm{Co}_{3} \mathrm{O}_{4}$ were obtained with dominance of $\mathrm{Co}_{3} \mathrm{O}_{4}$ phase. This substantiates that the sulphur moiety from the polymer has reacted with the cobalt precursor. The diffraction peak at 26.7, 31.4, 38.1, 55.1 correspond to cubic $\mathrm{Co}_{3} \mathrm{~S}_{4}$, (JCPDS No. 47-1738) whereas the peak at 36.8 corresponds to $\mathrm{Co}_{3} \mathrm{O}_{4}$. The peak observed at $2 \theta$ value of $20.5^{\circ}$ in Figures 1(b)-(d) matches with PPS.

The images in Figure 2 elucidate the FESEM images for the obtained nanocomposites for the various ratios of cobalt precursor to PPS polymer. Formation of irregular shape morphology having size in the range of $30 \mathrm{~nm}$ to $100 \mathrm{~nm}$ is observed for the 1:1 ratio (Figure 2(a)). Uniform distribution of the $\mathrm{Co}_{3} \mathrm{~S}_{4}$ and $\mathrm{Co}_{3} \mathrm{O}_{4}$ is observed for the higher proportion of PPS (Figures 2(c) and (d)). The composition with 1:10 cobalt to polymer shows uniform distribution with the average particle size of $30 \mathrm{~nm}$.

The HRTEM analysis is shown in Figure 3. The formation of nanoparticles embedded in the PPS matrix is observed for the $\mathrm{Co}_{3} \mathrm{O}_{4}$ prepared using 1:1 ratio. The average particle size for the resultant composition was found to be in between 5 to $10 \mathrm{~nm}$. The SAED pattern shown as inset of Figure 3(a) indicates the formation of cubic $\mathrm{Co}_{3} \mathrm{O}_{4}$, which is also evident from the XRD analysis for the resultant nanocomposites. The interplanar

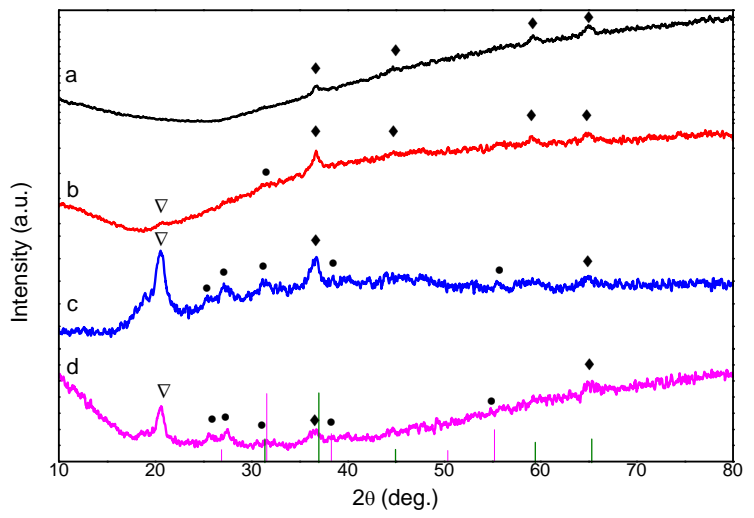

Figure 1. XRD patterns of $\mathrm{Co}_{3} \mathrm{O}_{4}$ and $\mathrm{Co}_{3} \mathrm{~S}_{4}$, samples of Cobalt to PPS ratios where (a) 1:1, (b) 1:5, (c) 1:10, (d) 1:15 $(\bullet)$ indicates oxide peaks, $(\bullet)$ indicates sulphide peaks and $(\nabla)$ corresponds to PPS peak. Pink line indicates the JCPDS No. (47-1738) corresponding to $\mathrm{Co}_{3} \mathrm{~S}_{4}$ and green line indicates the JCPDS No. (42-1467) corresponding to $\mathrm{Co}_{3} \mathrm{O}_{4}$. 


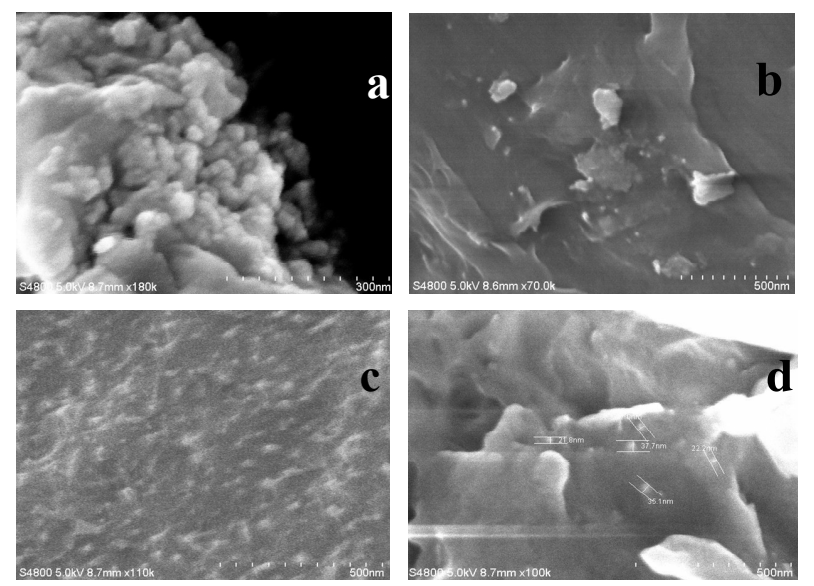

Figure 2. FESEM images for the resultant products for different ratios of Cobalt Nitrate precursor to PPS where (a) 1:1, (b) 1:5, (c) 1:10 and (d) 1:15. (Scale bars: $300 \mathrm{~nm}$ for Figure (a) and $500 \mathrm{~nm}$ for Figures (b)-(d), respectively).
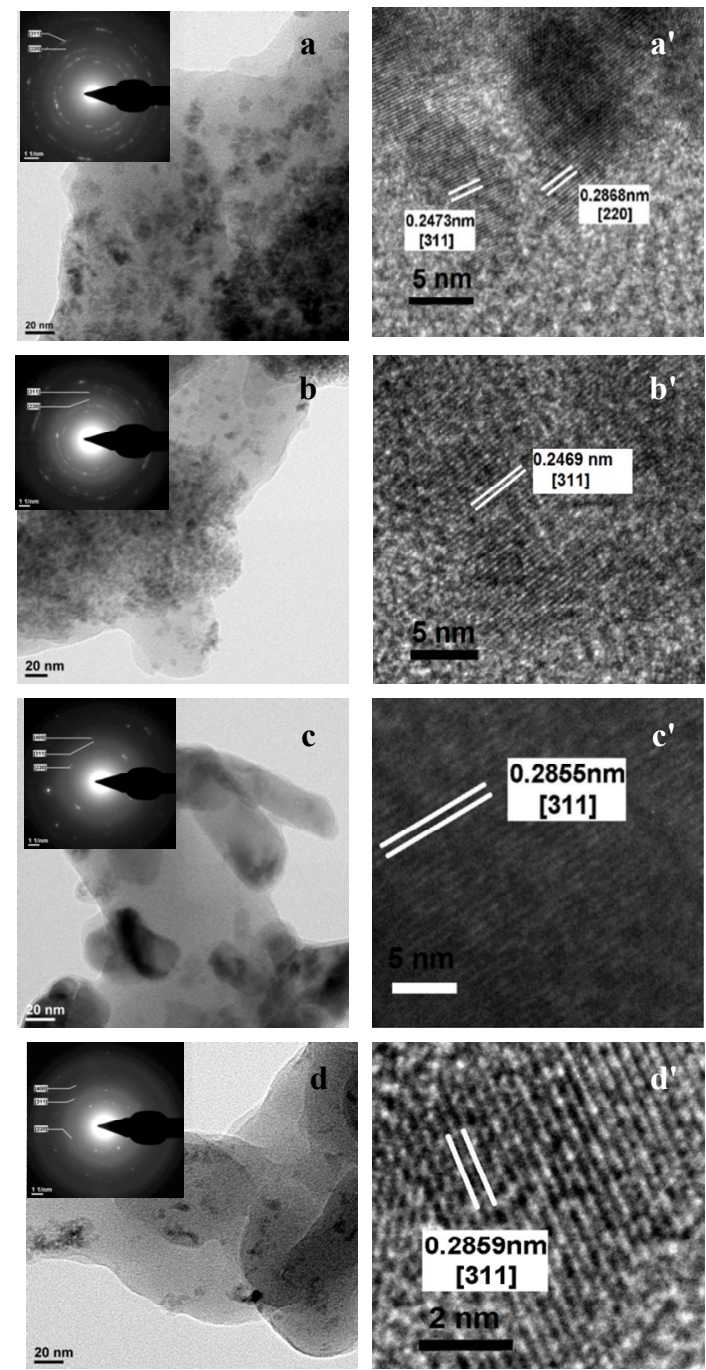

Figure 3. HRTEM images for the material for different ratios of Cobalt Nitrate precursor to PPS where (a) 1:1, (b) 1:5, (c) 1:10 and (d) 1:15. spacing of 0.24 and 0.28 corresponds to (311) and (220) planes, respectively, thereby indicating the formation of crystalline $\mathrm{Co}_{3} \mathrm{O}_{4}$. HRTEM analysis of nanocomposites prepared using 1:5 ratio also indicates formation nano sized $\mathrm{Co}_{3} \mathrm{O}_{4}$ having size in the range of 5 to $10 \mathrm{~nm}$. Slight agglomerations of nano particles are observed. The SAED pattern and the lattice spacing (Figures 3(b) and $\left.\left(\mathbf{b}^{\prime}\right)\right)$ confirms the formation of cubic $\mathrm{Co}_{3} \mathrm{O}_{4}$ and also supports the XRD analysis. For higher ratio (1:10 and $1: 15)$ the formation of distorted rod like morphology was observed. The SAED pattern and lattice spacing indicates the formation of $\mathrm{Co}_{3} \mathrm{~S}_{4}$ (Figures 3(c), (c') and (d), (d')) with lattice spacing of 0.2855 matching well with (311) plane of $\mathrm{Co}_{3} \mathrm{~S}_{4}$.

DRS spectra of prepared nanocomposites are depicted in Figure 4. PPS indicates the absorption edge at $390 \mathrm{~nm}$. The band edge of the nanocomposites was located at 790 $\mathrm{nm}(1.5 \mathrm{eV})$, had a blue shift of approximately $288 \mathrm{~nm}$ with respect to the band gap of $1078 \mathrm{~nm}(1.15 \mathrm{eV})$ for bulk $\mathrm{Co}_{3} \mathrm{~S}_{4}$. The hump centered at $750 \mathrm{~nm}$ corresponds to the band gaps of $\mathrm{Co}_{3} \mathrm{O}_{4}$ and $\mathrm{Co}_{3} \mathrm{~S}_{4}$ which, interestingly, are almost in the same range $[17,18]$.

The FTIR spectra obtained for neat PPS and the resultant nanocomposites are depicted in Figure 5. Characteristic bands of PPS are observed at $1471 \mathrm{~cm}^{-1}$ due to stretching vibration of $\mathrm{C}=\mathrm{C}$ in benzene and $818 \mathrm{~cm}^{-1}$ due

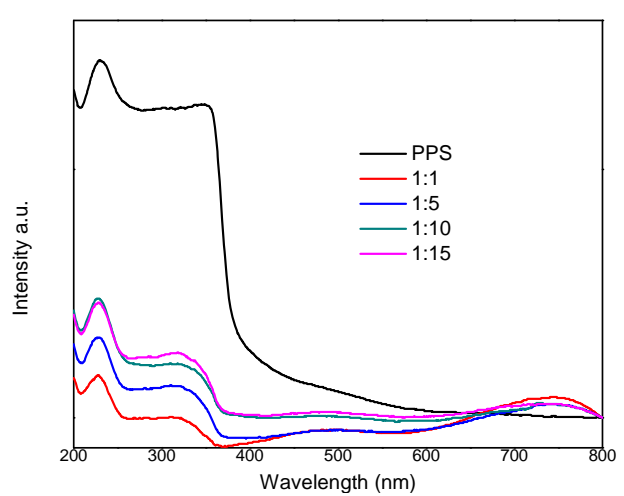

Figure 4. DRS of pure PPS and samples prepared using cobalt salt to PPS ratios of $1: 1,1: 5,1: 10,1: 15$, respectively.

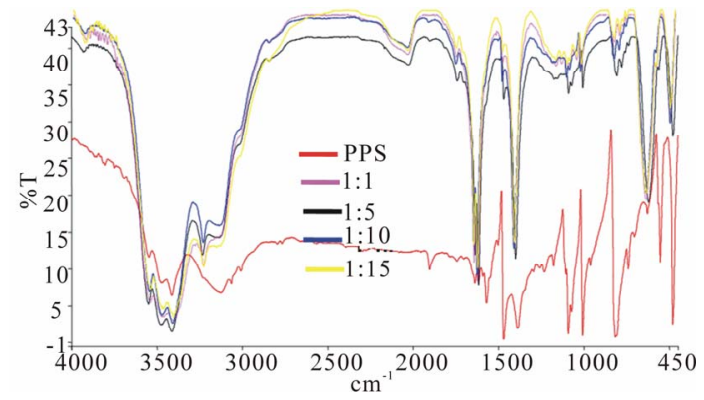

Figure 5. FTIR spectra of pure PPS and samples prepared using cobalt salt to PPS ratios of 1:1, 1:5, 1:10, 1:15, respectively. 
to deformation vibration of $=\mathrm{C}-\mathrm{H}$ in 1,4 place of benzene, also numerous sharp bands at $1091 \mathrm{~cm}^{-1}, 1008$ $\mathrm{cm}^{-1}$, and $485 \mathrm{~cm}^{-1}$ which may be attributed to the crystalline nature of PPS are observed in Figure 5(a). In the spectra for nanocomposites of various ratios (Figures 5(b)-(e)), the peaks at $624 \mathrm{~cm}^{-1}$ are characteristics of metal oxide bands. A peculiar peak at $2030 \mathrm{~cm}^{-1}$ is observed for the resultant nanocomposites.

\section{Conclusion}

In summary, we have successfully synthesized cobalt sulphide/oxide nanoparticles in polymer matrix by facile solid-solid reaction technique. The formation of cubic structure $\mathrm{Co}_{3} \mathrm{O}_{4}$ and $\mathrm{Co}_{3} \mathrm{~S}_{4}$ embedded in the PPS matrix was confirmed by XRD and HRTEM. This technique, being quite simple, can be used for preparation of nanocomposites for future generation smart materials. The polymer PPS being an engineering thermoplastic with inherent flame retardant characteristics can be molded as desired for advanced device fabrication.

\section{Acknowledgements}

One of the authors (N. P. Rumale) sincerely acknowledges to the Managing Director of ELANTAS Beck India Ltd. Mr. Rajeev Bhide, the Managing Director of Icon Analytical Equipment Pvt. Ltd., Mr. Anand Rao, Dr. B. B. Kale, Scientist, Centre for Materials for Electronics Technology (C-MET) for their kind support in carrying out this work.

\section{REFERENCES}

[1] L. F. Nicolais and G. Carotenuto, "Synthesis of Polymer-Embedded Metal, Semimetal, or Sulfide Clusters by Thermolysis of Mercaptide Molecules Dissolved in Polymers," Recent Patents on Materials Sciences, Vol. 1, No. 1, 2008, pp. 1-11. doi:10.2174/1874464810801010001

[2] X. H. Liu, "Hydrothermal Synthesis and Characterization of Nickel and Cobalt Sulfides Nanocrystallines," Materials Science and Engineering B, Vol. 119, No. 1, 2005, pp. 19-24. doi:10.1016/j.mseb.2004.12.051

[3] L. P. Deshmukh and S. T. Mane, "Liquid Phase Chemical Deposition of Cobalt Sulphide Thin Films: Growth and Properties," Digest Journal of Nanomaterials and Biostructures, Vol. 6, No. 3, 2011, pp. 931-936.

[4] H. Yang, Y. Hu, X. Zang and G. Qui, "Mechanochemical Synthesis of Cobalt Oxide Nanoparticles," Materials Letters, Vol. 58, No. 3-4, 2004, pp. 387-389. doi:10.1016/S0167-577X(03)00507-X

[5] G. H. Yue, P. X. Yan, X. Y. Fan, M. X. Wang, D. M. Qu, Z. G. Wu, C. Li and D. Yan, "Structure and Properties of Cobalt Disulfide Nanowire Arrays Fabricated by Electrodeposition," Electrochemical and Solid-State Letters, Vol. 10, No. 3, 2007, pp. D29-D31. doi:10.1149/1.2430564
[6] Y. Yin, C. K. Erdonmez, A. Cabot, S. Hughes and A. P. Alvistatos, "Colloidal Synthesis of Hollow Cobalt Sulfide Nanocrystals," Advanced Functional Materials, Vol. 16, No. 11, 2006, pp. 1389-1399.

doi:10.1002/adfm.200600256

[7] K. Y. Niu, J. Yang, S. A. Kulinich, J. Sun and X. W. Du, "Hollow Nanoparticles of Metal Oxides and Sulfides: Fast Preparation via Laser Ablation in Liquid," Langmuir, Vol. 26, No. 22, 2010, pp. 16652-16657. doi:10.1021/la1033146

[8] P. Justin and G. R. Rao, "CoS Spheres for High Rate Electrochemical Capacitive Energy Storage Application," International Journal of Hydrogen Energy, Vol. 35, No. 18, 2010, pp. 9709-9715. doi:10.1016/j.ijhydene.2010.06.036

[9] S. J. Bao, Y. Li, C. M. Li, Q. Bao, Q. Lu and J. Guo, "Shape Evolution and Magnetic Properties of Cobalt Sulfide," Crystal Growth Design, Vol. 8, No. 7, 2008, pp. 3745-3749. doi:10.1021/cg800381e

[10] N. Khaorapapong, A. Ontam and M. Ogawa, "Very Slow Formation of Copper Sulfide and Cobalt Sulfide Nanoparticles in Montmorillonite," Applied Clay Science, Vol. 51, No. 1, 2011, pp. 182-186. doi:10.1016/i.clay.2010.10.030

[11] C. R. Indulal, G. S. Kumar, A. V. Vaidyan and R. Raveendran, "Oxide Nanostructures: Characterisations and Optical Band Gap Evaluations of Cobalt Manganese and Nickel at Different Temperatures", Journal of Nano- and Electronic Physics, Vol. 3, No. 1, 2011, pp. 170-178.

[12] K. GézaSzabó and M. Zrínyi, "Liquid-Phase Synthesis of Cobalt Oxide Nanoparticles," Journal of Nanoscience and Nanotechnology, Vol. 11, No. 5, 2011, pp. 1-9.

[13] F. I. Ezema, "Preparation and Optical Characterization of Chemical Bath Deposited $\mathrm{CdCoS}_{2}$ Thin Films," Journal of Applied Sciences, Vol. 6, No. 8, 2006, pp. 1827-1832. doi:10.3923/jas.2006.1827.1832

[14] T. Yu, Y. Zhu, X. Xu, Z. Shen, P. Chen, C. T. Lim, J. Thiam, L. Thong and C. H. Sow, "Controlled Growth and Field Emission Properties of Cobalt Oxide Nanowalls," Advanced Materials, Vol. 17, No. 13, 2005, pp. 15951599. doi:10.1002/adma.200500322

[15] S. R. Ahmed and P. Kofinas, "Magnetic Properties and Morphology of Block Copolymer-Cobalt Oxide Nanocomposites," Journal of Magnetism and Magnetic Materials, Vol. 288, 2005, pp. 219-223.

doi:10.1016/j.jmmm.2004.09.009

[16] J. Pyun, "Nanocomposite Materials from Functional Polymers and Magnetic Colloids," Polymer Reviews, Vol. 47, No. 2, 2007, pp. 231-263. doi:10.1080/15583720701271294

[17] N. Mathur, R. K. Joshi, G. V. Subbaraju and H. K. Sehgal, "Solution Grown $\mathrm{Pb}_{1-\mathrm{x}} \mathrm{Co}_{\mathrm{x}} \mathrm{S}$ Semiconductor Nanoparticle Film," Physica E: Low-Dimensional Systems and Nanostructures, Vol. 23, No. 1-2, 2004, pp. 56-60.

[18] L. He, Z. Li and Z. Zhang, "Rapid, Low-Temperature Synthesis of Single Crystalline $\mathrm{Co}_{3} \mathrm{O}_{4}$ Nanorods on Silicon Substrates on a Large Scale," Nanotechnology, Vol. 19, No. 15, 2008, Article ID: 155606. doi:10.1088/0957-4484/19/15/155606 